\title{
PERANCANGAN PEMBANGKIT LISTRIK TENAGA MIKROHIDRO. STUDI KASUS DI CURUG CIGEUNTIS, KECAMATAN TEGALWARU, KABUPATEN KARAWANG,
}

\author{
JAWA BARAT \\ ${ }^{1}$ Bayu Suryo Wiranto, ${ }^{2}$ Muhammad Rif'an, ${ }^{3}$ Massus Subekti \\ 1,2,3 Pendidikan Teknik Elektro, Fakultas Teknik, Universitas Negeri Jakarta \\ 1,2,3 Email: bayu_suryowiranto@yahoo.com,m.rifan@yahoo.co.id, massus@unj.ac.id
}

\begin{abstract}
This research aims to create a design model of microhydro powerplant, and implement that design model to particular location, which decided location in this research is Cigeuntis Waterfall. Output of this research can be utilized by microhydro power plant practitioners as a tool, and stakeholders to valuing natural resources potential in their area. Cigeuntis Waterfall is selected because it has sufficient water in raining season, and more important, in dry season. Analysis descriptive method is used in this research with qualitative approach. Technics of Engineering is type of this research, encompassing design formulation of microhydro power plant, formula validation by comparing design of microhydro power plant based on formula with existing microhydro power plant in PLN Laboratory, and designing microhydro power plant components like intake, settling basin, penstock pipe, turbine, pulley, and generator regarding water flow and net head of Cigeuntis Waterfall.

Results of this research are if microhydro power plant build at Cigeuntis Waterfall with $0.55 \mathrm{~m}^{3} / \mathrm{s}$ water flow and net head is $25 \mathrm{~m}$, the size of components must be $2.97 \mathrm{~m}^{2}$ for intake, $6.6 \mathrm{~m} \times 0.83 \mathrm{~m} \times 2.2 \mathrm{~m}$ for settling basin, $48 \mathrm{~cm}$ for penstock diameter and $0.17 \mathrm{~cm}$ for its thickness, 11.81 inch for turbine diameter and 3.8 inch for its length, 2.1 inch for blade turbine space, 18 blades turbine needed, 11.81 inch for pulley diameter which connected to turbine and 5.2 inch diameter which connected to generator, and capacity of generator is $104.1 \mathrm{~kW}$.

This formula created in Microsoft Excel format, and after validation with existing microhydro power plant, there is not any substantial difference as the result. Therefore, the conclusion is this design model of microhydro power plant able to be implemented.
\end{abstract}

Keywords: Microhydro power plant, Designing microhydro power plant, Microhydro

\begin{abstract}
Abstrak
Penelitian ini bertujuan untuk menghasilkan model perancangan PLTMH, dan mengimplementasikannya pada lokasi tertentu, yang pada penelitian ini ditetapkan lokasinya adalah Curug Cigeuntis. Model perancangan ini nantinya bisa digunakan oleh para perancang PLTMH sebagai observasi awal, dan juga digunakan oleh para pemangku kebijakan dalam melihat potensi sumber daya alam di daerahnya. Curug Cigeuntis dipilih menjadi lokasi pengujian sebagai contoh implementasi yang dari model perancangan yang dibuat karena ketersediaan air di sana boleh dikatakan tinggi akibat curah hujan yang besar.

Penelitian ini menggunakan metode deskriptif analisis melalui pendekatan kualitatif. Jenis penelitian yang dipilih ialah rekayasa teknik dengan mencangkup pembuatan formulasi perancangan PLTMH, validasi formulasi perancangan PLTMH dengan acuan sistem PLTMH yang terpasang pada Laboratorium Tenaga Air Mini milik PLN, dan perancangan bagian PLTMH, yaitu saluran intake, bak penenang, pipa penstock, turbin, pulley, dan generator mempertimbangkan kondisi alam seperti debit air dan tinggi jatuh air pada Curug Cigeuntis.

Hasil penelitian menunjukan bahwa Curug Cigeuntis dengan debit andalan sebesar $0.55 \mathrm{~m}^{3} / \mathrm{s}$ dan tinggi jatuh air sebesar $25 \mathrm{~m}$, diperoleh ukuran intake

$2.97 \mathrm{~m}^{2}$, ukuran bak penenang $6.6 \mathrm{~m}$ x $0.83 \mathrm{~m}$ x $2.2 \mathrm{~m}$, ukuran diameter penstock $48 \mathrm{~cm}$ dan ketebalannya $0.17 \mathrm{~cm}$, ukuran diameter turbin 11.81 inch dengan panjang 3.8 inch, jarak antara pisau 2.1 inch, dan jumlah pisau turbin sebanyak 18 buah. Ukuran pulley besarnya pada bagian diameter terhubung turbin adalah 11.81 inch dan diameter terhubung generator 5.2 inch. Kapasitas generator yang digunakan sebesar $104.1 \mathrm{kw}$.

Formulasi perancangan yang dibuat menggunakan program Microsoft Excel, telah divalidasi dengan sistem PLTMH terpasang dan tidak didapati perbedaan yang substansial sehingga dapat disimpulkan perancangan PLTMH layak untuk diimplementasikan pada perancangan tertentu.
\end{abstract}

Kata kunci: PLTMH, Perancangan PLTMH, Mikrohidro

\section{PENDAHULUAN}

Energi adalah kebutuhan sehari-hari manusia secara individu, dalam bentuk konsumsi pribadi, maupun manusia secara kelompok, dalam bentuk konsumsi untuk perusahaan dan pelayanan publik. Mengingat pertumbuhan jumlah manusia terus bertambah dengan presentasi $1 \%$ di setiap tahunnya (RUPTL 2016-2025, 2016: 121), tentu kebutuhan energi ikut bertambah. Kebutuhan 
tersebut belum termasuk $16 \%$ masyarakat yang belum mendapatkan listrik, karena saat ini rasio elektrifikasi baru menyentuh angka 84\% (RUPTL 2015-2024, 2015:29).

Pemenuhan energi demikian dihadapkan dengan kendala, mengigat menghasilkan listrik dengan cara konvensional memberikan dampak buruk bagi lingkungan, seperti $\mathrm{CO} 2$ dan $\mathrm{CO}$ yang terhempaskan ke udara dan kemudian merusak lapisan ozon di atmosfer.

Menghadapi permasalahan demikian, pemerintah berupaya melalui Keputusan Menteri Energi dan Sumber Daya Mineral nomor 5899 K/20/MEM/2016, terkait Rencana Usaha Penyediaan Tenaga Listrik (RUPTL) tahun 2016-2025. RUPTL ini menargetkan pembangunan pembangkit $35.000 \mathrm{MW}$ demi memenuhi kebutuhan listrik saat ini dan di masa yang akan datang. Dari 35.000 MW pembangkit yang direncanakan, pemerintah berkomitmen $25 \%$ diantaranya disumbang dari pembangkit energi baru terbarukan (EBT).

Sebagai upaya membantu terwujudnya RUPTL, mikro hidro mempunyai peluang cukup baik karena di Indonesia banyak tersedia sumber air dalam bentuk air terjun, tidak menghasilkan polusi, dan produksi listriknya cukup untuk wilayah pedalaman. PLTMH harus bertempatan pada salah satu provinsi yang memiliki banyak lokasi dengan ketersediaan air memumpuni, dan berdampak signifikan bagi wilayah tersebut.

Provinsi Jawa Barat menjadi pilihan tepat untuk difokuskan pada projek PLTMH dikarenakan provinsi Jawa Barat mempunyai curah hujan tahunan sebesar 2.199 per-mm (bps.go.id). Bagian dari provinsi Jawa Barat untuk dijadikan lokasi penelitian ini adalah Kabupaten Karawang, tepatnya di Curug Cigeuntis, Kecamatan Tegalwaru. Dengan ketinggian jatuh air sebesar $25 \mathrm{~m}$, dan debit air sebesar $0.55 \mathrm{~m}^{3} / \mathrm{s}$, ditaksir potensi listrik yang dihasilkan sebesar $\pm 100 \mathrm{~kW}$.

\section{METODE PENELITIAN}

Penelitian ini dilaksanakan di Curug Cigeuntis, Kecamatan Tegalwaru, Kabupaten Karawang, Jawa Barat. Penelitian ini menggunakan alat laser distance meter, tongkat, jangka sorong, dan meteran bangunan demi mendapat data ukuran hasil pengamatan di lapangan.

Data yang terdapat pada penelitian ini diperoleh melalui dua cara, yakni teknik pengumpulan data primer dan teknik pengumpulan data sekunder. Teknik pengumpulan data primer meliputi observasi lapangan, yang mana data tersebut adalah hasil dari kejadian dilapangan ketika dilakukan pengukuran atau wawancara. Sedangkan, ihwal teknik pengumpulan data sekunder meliputi pembacaan pada studi literature dengan buku atau artikel jurnal sebagai refrensinya. Setelah data didapat, kemudian dilakukanlah pengolahan menggunakan formulasi yang didapat untuk memperoleh ukuran dari masingmasing komponen PLTMH mengacu pada kondisi Curug Cigeuntis.

\section{HASIL DAN PEMBAHASAN \\ Kondisi Curug Cigeuntis}

Dalam melakukan perancangan PLTMH di Curug Cigeuntis, perlu diketahui terlebih dahulu kondisi sungai tersebut. Kondisi sungai ini meliputi ketinggian jatuh air dan debit air. Perihal ketinggian jatuh air, melalui pengukuran menggunakan alat laser distance meter, diperoleh angka 25 meter.

Setelah mendapat ketinggian jatuh air, langkah berikutnya adalah mendapatkan lebar sungai dan kedalaman sungai. Besarnya lebar sungai dan kedalaman sungai didapat melalui pengukuran sampel pada bagian sungai sebanyak 5 kali pengukuran. Hasil pengukuran lebar dan kedalaman sungai dari Curug. Cigeuntis dipaparkan pada Tabel 1 dan Tabel 2.

Tabel 1. Hasil Pengukuran Lebar Sungai

\begin{tabular}{|c|c|}
\hline No & Hasil Pengukuran \\
\hline 1 & 1,1 meter \\
\hline 2 & 2,8 meter \\
\hline 3 & 3,5 meter \\
\hline 4 & 3,9 meter \\
\hline 5 & 3,7 meter \\
\hline
\end{tabular}


Tabel 2. Hasil Pengukuran Kedalaman Sungai

\begin{tabular}{|c|c|}
\hline No & Hasil Pengukuran \\
\hline 1 & 1,1 meter \\
\hline 2 & 1,2 meter \\
\hline 3 & 1,3 meter \\
\hline 4 & 1 meter \\
\hline 5 & 0,9 meter \\
\hline
\end{tabular}

Mengacu pada nilai hasil pengukuran lebar sungai di Tabel 1, kita hitung rata-rata nilainya adalah 3 meter, sehingga asumsi ukuran lebar sungai dari Curug Cigeuntis adalah 3 meter. Lalu, soal kedalaman sungai, mengacu pada hasi pengukuran yang terpapar pada Tabel 2, melalui rata-rata nilai, dapat diketahui lebar dari sungai di Curug Cigeuntis adalah 1.1 meter.

Sedangkan, dalam pengukuran debit air, data diambil melalui 12 kali pengukuran. Rentan waktu pengukuran adalah 10 menit, sehingga lama waktu pengukuran ialah 120 menit. Dari sekian banyak data yang diperoleh, nilai debit air berasal dari nominal debit yang terjadi sebanyak $80 \%$ dari serangkaian pengukuran. Nilai debit dari 12 kali pengukuran tersebut dapat dilihat pada Tabel 3.

Tabel 3. Hasil Pengukuran Debit Air

\begin{tabular}{cc}
\hline No & Debit Air $\left(\mathbf{m}^{\mathbf{3}} / \mathbf{s}\right)$ \\
\hline 1 & 0,56 \\
2 & 0,55 \\
3 & 0,56 \\
4 & 0,54 \\
5 & 0,57 \\
6 & 0,59 \\
7 & 0,58 \\
8 & 0,57 \\
9 & 0,56 \\
10 & 0,55 \\
11 & 0,54 \\
12 & 0,55 \\
\hline
\end{tabular}

Berdasarkan hasil pengukuran yang ditampilkan pada Tabel 1, besarnya debit air yang terjadi sebanyak $80 \%$ dari 12 kali pengukuran ialah $0.55 \mathrm{~m}^{3} / \mathrm{s}$. Alhasil, $0.55 \mathrm{~m}^{3} / \mathrm{s}$ menjadi acuan dalam melakukan perancangan komponen PLTMH.

\section{Perancangan Komponen PLTMH Di Curug Cigeuntis}

Pada pengukuran debit air seperti paparan melalui Tabel 1, diketahui nominal debit air yang $80 \%$ terjadi sebesar $0.55 \mathrm{~m}^{3} / \mathrm{s}$. Oleh karenanya, perhitungan masing-masing komponen PLTMH mengacu pada nilai debit air ini.

\section{Perancanan Saluran Intake}

Memerhatikan formulasi yang telah ditulis pada bagian sebelumnya, ukuran saluran intake didapat melalui perhitungan sebagai berikut:

\section{Ukuran Intake $=90 \% \times$ Dth $\times \ell$ \\ Ukuran Intake $=90 \% \times 1.1 \times 3$}

Ukuran Intake $=2.97 \mathrm{~m}^{2}$.

Melalui hasi perhitungan tersebut, didapatkan ukuran intake pada PLTMH yang hendak dibangun di Curug Cigeuntis sebesar $2.97 \mathrm{~m}^{2}$

\section{Perancangan Bak Penenang}

Menentukan ukuran bak peneneng, kita mengacu pada nominal debit dari tempat bersangkutan. Semakin besar nilai debit air, semakin besar pula ukuran bak penenang yang hendak dibuat.

Ada tiga ukuran bak penenang yang didapat melalui formulasi perancangan, yakni panjang, lebar, dan kedalaman. Untuk kondisi Curug Cigeuntis, ukuran bak penenangnya dengan panjang 8,94 meter, lebar 1,12 meter, dan kedalaman sebesar 2,98 meter. Debit air sebesar $0,55 \mathrm{~m}^{3} / \mathrm{s}$.

\section{Perancangan Pipa Penstock}

Selain mempengaruhi ukuran bak penenang, debit air juga mempengaruhi ukuran pipa penstock. Semakin besar nilai debit air, maka semakin besar pula ukuran pipa penstock ini.

Ada dua hal dari pipa penstock yang besarnya ditentukan melalui formulasi rancangan. Kedua hal tersebut adalah ketebalan pipa dan diameter pipa. Hasil perhitungannya yaitu nilai diameter pipa penstock sebesar $50 \mathrm{~cm}$ dan ketebalan sebesar 0,21 $\mathrm{cm}$. Nilai tersebut pada implementasinya bisa lebih besar, menyesuaikan dengan kondisi sekitar yang hendak dibangun PLTMH. 


\section{Perancangan Turbin}

Turbin yang digunakan pada perancangan PLTMH ini adalah turbin crossflow. Ukuran turbin ini bergantung pada besarnya nilai debit air dan ketinggian jatuh air. Semakin besar debit air, ukuran turbin akan semakin besar pula. Hanya saja, jika ketinggian jatuh air yang besar, maka ukuran turbin akan mengecil.

Terdapat tujuh ukuran dari turbin crossflow yang ditentukan melalui perancangan, sedangkan terdapat satu ukuran yang ditentukan secara given. Ukuran yang given ini adalah diameter turbin dengan nilai 11,81 inch. Nilai diameter ditentukan lebih dahulu demi kemudahan perancangan. Untuk ketujuh ukuran lainnya dari turbin diperoleh panjang turbin sebesar 3,8 inch, diameter pitch circle sebesar 8,9 inch, diameter shaft sebesar 2,6 inch, ketebalan pisau turbin sebesar 1 inch, jarak antar pisau sebesar 2 inch, dan jumlah pisau sebesari 18 bilah.

\section{Perancangan generator}

Bagian dari generator yang ditentukan melalui formulasi perancangan ini adalah kapasitas generatornya. Melalui formulasi perancangan yang telah dibuat, didapatkan nilai kapasitas generator yang sesuai untuk PLTMH di Curug Cigeuntis sebesar $83.28 \mathrm{~kW}$. Pada implementasinya, pemilihan kapasitas generator perlu juga melihat kapasitas yang tersedia di pasaran, dan tentu kapasitas tersebut harus lebih besar ketimbang nilai hasil perancangan.

\section{Perancangan Pulley}

Terdapat dua bagian pulley yang dirancangn pada formulasi perancangan ini, yakni diameter pulley terhubung turbin dan diameter pulley terhubung generator. Besarnya diameter pulley terhubung turbin disesuaikan dengan diameter turbinnya demi kemudahan perancangan.

Ihwal diameter pulley terhubung generator, nilai diameter pulley yang terhubung generator sebesar 5,204 inch.

\section{KESIMPULAN DAN SARAN Kesimpulan}

1. Model perancangan PLTMH meliputi bangun hidrolik dan komponen elektromekanik. Bangun hidrolik ini terdiri dari saluran intake, bak penenang, dan pipa penstock. Komponen elektromekanik terdiri dari turbin, generator, dan pulley.

2. Ukuran bak penenang terbagi atas tiga jenis, yaitu ukuran panjang, lebar, dan kedalaman. Semakin besar nilai debit air (Q), semakin besar panjang bak penenang.

3. Dalam merancang pipa penstock, terdapat dua ukuran yang diperhatikan, yakni diameter pipa dan ketebalan pipa. Semakin besar ukuran diameter pipa, semakin besar ketebalan pipa tersebut.

4. Turbin pada PLTMH memiliki beberapa bagian untuk dirancang. Bagian tersebut adalah diameter turbin, panjang turbin, diameter pitch circle, diameter diameter shaft, ketebalan pisau turbin, jarak antara pisau turbin, dan jumlah pisau turbin. Diameter turbin ditetapkan sebesar 11.81 inch. Dari perhitungan didapatkan panjang turbin dipengaruhi oleh besarnya debit air dan tinggi jatuh air. Nilai ketebalan pisau, jarak antara pisau, dan jumlah pisau, besarnya bergantung pada nilai diameter.

5. Besarnya kapasitas generator ini mengacu pada kemungkinan besarnya listrik yang dihasilkan, dan nilai tersebut mengacu daya yang dihasilkan turbin. Untuk itu, pertamatama ditentukan besarnya daya yang dihasilkan Kemudian, hasilnya digunakan untuk menghitung kemungkinan besarnya listrik yang dihasilkan. Hasil dari perhitungan besarnya listrik yang dihasilkan kemudian digunakan untuk menentukan kapasitas generator yang hendak digunakan.

6. Pulley merupakan komponen terakhir dari PLTMH yang ditentukan ukurannya. Ukuran pulley terbagi atas dua jenis, yakni ukuran diameter pulley terhubung turbin, dan ukuran diameter pulley terhubung generator. Besar keduanya ditentukan melalui nominal putaran turbin dan putaran generator. Ihwal putaran generator, nominalnya mengacu pada karakteristik barangnya yang diasumsikan sebesar 1500 
rpm. Untuk ukuran diameter pulley sendiri, demi mempermudah hitungan, ukuran diameter pulley terhubung turbin besarnya disamakan dengan turbinnya, sehingga hanya perlu mencari nilai dari diameter pulley terhubung generator.

7. Dengan debit air di Curug Cigeuntis sebesar $0.55 \mathrm{~m}^{3} / \mathrm{s}$, tinggi jatuh air sebesar 25 meter, dan lebar serta kedalaman sungai sebesar 3 meter dan 1.1 meter, didapati ukuran saluran intake sebesar $2.97 \mathrm{~m}^{2}$, ukuran bak penenang dengan panjang 6.6 meter; lebar 0.83 meter; kedalaman 2.2 meter, ukuran pipa penstock dengan diameter sebesar 50.2 $\mathrm{cm}$ dan ketebalan pipa sebesar $0.21 \mathrm{~cm}$. Selanjutnya, ukuran turbin dengan diameter sebesar 11.81 inch; panjang 3.8 inch; diameter pitch circle 8.9 inch; diameter shaft 2.6 inch; ketebalan pisau 1.033 inch; jarak antar pisau 2.067 inch; jumlah pisau 18 bilah Untuk kapasitas generator yang digunakan adalah $104.1 \mathrm{~kW}$, dengan diameter pulley sebesar 11.81 inch dan 5.204 inch.

\section{Saran}

Perlu dilakukannya penghematan menyeleruh pada wilayah yang ingin dibangun PLTMH demi penentuan lokasi masing-masing.

\section{DAFTAR PUSTAKA}

Arismunandar, Artono \& Kuwahara, Susumu. (1974). Buku Pegangan Teknik Tenaga Listrik 1. Jakarta: Pradnya Paramita.

[BPS] Badan Pusat Statistik. Jumlah Curah Hujan dan Jumlah Hari Hujan di Stasiun Pengamatan BMKG, 2011-2015, akses online 18 Agustus 2017, URL: https://www.bps.go.id/linkTa belStatis/view/id/1959.

[BPS] Badan Pusat Statistik Kabupaten Karawang. Keadaan Curah Hujan Tiap Bulan Menurut Kecamatan (mm) Kabupaten Karawang Tahun 2013, akses online 9 September 2017 URL: $\quad$ https://karawangkab.bps.go.i d/linkTabelStatis/view/id/10.
Bostan, I., et al. (2013). Resilient Energy Systems. London: Springer.

Castaldi, D., Chastain, E., Windram, M., \& Ziatyk, L. (2003). A Study of Hydroelectric Power: From a Global Perspective to a Local Application. Pennsylvania:The Pennsylvania State University.

Clemen, M.D. (1999). Hydro Plant Electrical Systems. Kansas City: HCI Publications.

Dandekar, M.M \& Sharma, K.N. (1979). Water Power Engineering. Noida: Vikas Publishing House.

Davis, Scott. (2003). Microhydro, Clean Power Form Water. Gabriola Island: New Society Publishers.

Department of Energy, Energy Utilization Management Bureau. (2009). Manuals and Guidelines for Mirco- hydropower Development in Rural Electrification.

Dwivedi, M., Srivastava, A.P., \& Raja, A.K. (2006). Power Plant Engineering. New Delhi: New Age International.

[ESHA] European Small Hydro Association. (2004). Guide on How To Develop a Small Hydropower Plant.

[IFC] International Finance Corporation. Hydroelectric Power, A Guide for Developers and Investors. Stuttgart: Fichtner.

Indayanti, D. (2009). Skripsi: Perbandingan Hasil Penentuan Curah Hujan Bulanan Menurut Teori Mohr Dan Oldeman Dengan Pendekatan Sistem Informasi Geografis, Program Studi Sistem Informasi Fakultas Sains dan Teknologi Universitas Islam Negeri Syarif Hidayatullah, Jakarta. 
Ismail, \& Supriono. 2013. Analisis Ekonomi Energi Perencanaan Pembangkit Listrik Tenaga Mikrohidro Meragun (Desa Meragun, Kec. Nanga Taman, Kab. Sekadau), Jurnal ELKHA Vol. 5, No.1 hal 31-40.

Khan, A, M., \& Badshah, S. (2014) Design and Analysis of Cross Flow Turbine for Micro Hydro Power Application using Sewerage Water, Research Journal of Applied Sciences, Engineering and Technology, Vol 8 pp. 821-828.

Leyland, B. (2014). Small Hydroelectric Engineering. Leiden: CRC Press.

[PLN] Perusahaan Listrik Negara. (2015). Rencana Usaha Penyediaan Tenaga Listrik (RUPTL)

Mockmore, C, A. \& Merryfield, F. (1949). The Banki Water Turbine. Oregon: Oregon State College.

Mott, L, R. (2004). Machine Elements in Mechanical Design. New Jersey: Pearson Prentice Hall.

Pudjanarsa, A \& Nursuhud, D. (2008). Mesin Konversi Energi. Yogyakarta: Penerbit ANDI.

Putro, Y, S, S., Juwono, P, T., \& Wicaksono, $\mathrm{P}, \mathrm{H}$. Studi Perencanaan Pembangkit Listrik Tenaga Mikro Hidro (PLTMH) Di Sungai Atei Desa Tumbang Atei Kecamatan Sanamang Mantikai Kabupaten Katingan Provinsi Kalimantan Tengah.

Purwanto. 2011. Analisis Finansial Dan Ekonomi Pembangkit Listrik Mikrohidro Di Beberapa Lokasi, Propinsi Jawa Tengah, Indonesia, Jurnal Penelitan Sosial dan Ekonomi Kehutanan Vol. 8 hal 251-264.

Ramos, H. (2000). Guideline For Design Of Small Hydropower Plants. Belfast: WREAN \& DED

Susatyo, A. (2003). Pengembangan Turbin Air Type Cross-Flow Diameter Runner 400 mm, Pemaparan Hasil Litbang hal 120.

Wibowo, N, A., Dermawan, V., Harisuseno., D. Studi Perencanaan Pembangkit Listrik Tenaga Mikrohidro (PLTMH) Wamena Di Kabupaten Jayawijaya Provinsi Papua.

Yusri., Roswaldi., Alwys, Munafri., Asmed. 2011. Rekayasa Turbin Air Jenis Cross Flow Sebagai Pembangkit Listrik Tenaga Mikro Hidro Jorong Lubuk Salasih, Kecamatan Gunung Talang, Kabupaten Solok, Jurnal Teknik Mesin Vol. 8 hal 72-77

Zuliari, E, A., Khomsah, A. (2014). Perencanaan Turbin Cross Flow Sudu Bambu Sebagai Pembangkit Listrik Tenaga Pico Hidro Kapasitas 200 Watt, Seminar Internasional Teknologi Terapan hal. 449- 458. 